\title{
Symbolic Perception in Kazakh Mythology
}

\section{Umit Anessova Garifullaevna}

Al-Farabi Kazakh National University, Kazakhstan, Almaty, al-Farabi ave. 71, 050038

Bagdan Momynova

Kazakh University of International Relations and World Languages named after Abylay khan Republic of Kazakhstan, Almaty, Muratbateva Street 200, 050000

\section{Saida Asetovna Saduakassova}

I.Zhansugurov Zhetisu State University, Kazakhstan, Taldykhorghan, Zhansugirov Street 187 A, 040000

Satkenova Zhaina

Al-Farabi Kazakh National University, Kazakhstan, Almaty, al-Farabi ave. 71, 050038

Doi:10.5901/mjss.2015.v6n6s2p145

\section{Abstract}

Symbol is a very ancient phenomenon as a constitute part of mythology. This paper highlights the issues of contemporary symbols connected with the national culture. The overview of different scholars' researches allows to identify the connection between mythology and symbols in other words and the symbolic perception of the world. The nature of the symbol is stable and kernel idea of symbols is transferred from generation to generation. Most of mythological heroes are described as symbols and nowadays they can have an influence on people's mentality and feelings. Among the Kazakh cultural symbols animalistic ones and symbols of flora, such as baiterek are presented vividly. The reconstruction of their cultural meanings highlights mythological understanding of the world. At the contemporary level of cultural development it is still possible to trace some of them.

Keywords: symbol, mythology, representation, language, cognition, culture, sign, cultural value, the symbolic manifestation.

\section{Introduction}

The main importance of the article is to show the connection of symbol and myth and the influence of them to people's perception of the world. How do they conduct, make people to do something and promote creation of the model of their life. Because we act according to our thoughts, which in turn are formed in consciousness in images and symbols. There are a great range of mythological symbols still living with us and become part of our imagination. In article such methods of research as supervision, the theoretical analysis and a deductive method are used.

One of the main means of communication and the tool, which help us to conduct our social life is language. When it is used within the context of communication, it bounds up with culture in a multiple and complex way, so we should consider the language as the way of expressing the language portrait of the world through the language and the culture of the nation, the way of thinking and expressing people's disposition.

First of all, the words people utter and think about refer to common experience. They express facts, ideas or events that are communicable because they refer to the knowledge about the world that other people share. Language also shows people's attitudes, beliefs, and viewpoints upon the world. In both cases language expresses cultural reality.

But members of common speech community do not only express the experience; they also create experience through language.

\section{Discussion}

According to following statement professor Uali N. claims that "self-influence of communicating people and 
communicative competence skills play an important role in speech act. Said words of adressee and the intention of speaker depends on adressees communicative competence" (Uali N., 2007).

Language is a system of signs that is seen as having itself a cultural value. Being the members of common speech community, people identify themselves through their use of language. That is why we can say that language symbolizes cultural reality.

Requirement to create a symbol is the main feature, which differentiates the human being from other inhabitants of the world. "The developmental transformation from animal to human existence entails a radical change in the nature of the transaction between the organism and its milieus: human beings are not merely, nor mainly, organisms reacting to stimuli or responding to things-of-action. Man forms his Umwelt by relating to his environments in a new manner: he is directed toward knowing. The orientation toward, and the capacity for, knowing are essential and irreducible characteristics of man, characteristics that come clearly into relief when one compares the nature of the adaptiveness of animals and men to their respective environments." (Werner, H., and B. Kaplan, 1963)

George Ferguson admits that: "There is a language for these experiences. It is a very simple and beautiful language which man has known and used since the beginning of time. It is called the language of the sign and the symbol, the outward and visible form through which the inward and invisible reality that moves and directs the soul of a man is revealed." (Ferguson, G., 1976)

Interesting explanation of symbol is given by Ricoeur P., who explains it as a manifestation of sacred: "First of all, then, it is the sun, the moon, the waters - that is to say, cosmic realities - that are symbols. Shall we say, therefore, that symbols, in their cosmic aspect, are interior to language, or even foreign to it? Not at all. For these realities to be a symbol is to gather together at one point a mass of significations which, before giving rise to thought, give rise to speech. The symbolic manifestation as a thing is a matrix of symbolic meanings as words. We have never ceased to find meanings in the sky... It is the same thing to say that the sky manifests the sacred and to say that it signifies the most high, the elevated and the immense, the powerful and the orderly, the clairvoyant and the wise, the sovereign, the immutable. The manifestation through the thing is like the condensation of an infinite discourse; manifestation and meaning are strictly contemporaneous and reciprocal; the concretion in the thing is the counterpart of the surcharge of inexhaustible meaning which has ramifications in the cosmic, in the ethical, and in the political. Thus the symbol-thing is the potentiality of innumerable spoken symbols which, on the other hand, are knotted together in a single cosmic manifestation" (Ricoeur P., 1969).

According to Karasik V.I. symbol can be described as following: "... the polysemy of a symbol represents not only possibility of its variable interpretation, but also consecutive plurality of interpretations. Generalizing the various characteristics of an art symbol manufactured in various works, devoted to its judgment, it is possible to give it the following definition: it is a perceptual image, characterized in the semantic depth, designating idea which possesses the high value, generating the new meanings, allowing the multiple interpretation, sending to supersensual experience" (Karasik, V.I., 2012).

Cirlot J.E. and J.Sage has more different opinion concerning symbol: "In the same way, the symbolic is true and active on one plane of reality, but it is almost unthinkable to apply it systematically and consistently on the plane of existence. The consequent skepticism concerning this plane of reality - the magnetic life-source of symbols and their concomitants - explains the whidespread reluctance to admit symbolical values; but such an attitude is lacking in any scientific justification" (Cirlot J.E. and J.Sage, 1962).

"Comparing with new researches, the langyage of symbolic actions functions according to history of a world, the life of a one person, it appears before the speech, but use it as a base in comprehension of symbols" (Ivanov V., 1985).

In her research, Aybarsha Islam considering symbols in the context of culture identifies them as means of conveying cultural information in a compact way ( Islam A., 2003).

From the ancient time man tried to overcome difficulties, chaos, disorder and other things by means of experience, learning something. "...Now it is our contention that in order to build up a truly human universe, that is, a world that is known rather than merely reacted to, man requires a new tool - an instrumentality that is suited for, and enables the realization of, those operations constituting the activity of knowing. This instrumentality is the symbol' (Werner, H., and B. Kaplan, 1963). Also Heinz Werner and Bernard Kaplan see the representative mark as the main function or feature of symbols. Also they disagree with B. Russel's opinion that symbol can be one of species of a "sign". According to them symbol is rather cognitive oriented than pragmatically. Edwyn Bevan claims: "So far as something seems to represent or stand for some reality other than itself, it may be considered as a symbol" (Bevan, E., 1950).

V.A.Maslova defined some independent representations of a symbol: 1) a symbol - the concept identical to a sign (in the artificial formalized languages); 2) the universal category reflecting specificity of figurative development of life by art (in an esthetics and art philosophy); 3) some cultural object, which of the value is conventional (i.e. fixed in 
dictionaries) analog of value of other object (in Cultural Studies, Sociology and in a number of other Humanities); 4) a symbol as a sign which assumes use of the primary maintenance as the form for other maintenance (the wide understanding of a symbol existing in many fields - Philosophy, Linguistics, Semiotics etc.). I.Kant, F.V.Schelling, V.F.Gegel and I.V.Goethe expressed a symbol as a way of knowledge of true divine sense (Maslova V.A., 2004).

According to Shelestyuk symbol is a multi-notion conventional sign which represents, apart from its inherent and immediate designatum, an essentially different, usually more abstract designatum, connected with the former by a logical link. In semantic terms, in symbols we deal with a hierarchy of meanings, where the direct meaning constitutes the first layer of sense and serves as a basis for the indirect (secondary) meaning - the second layer of sense, both of them united under the same designator (a name, a visual image, a significant object or person, etc.) ( Shelestiuk, Helen V. 2003).

Thus, the symbol is differently understood and defined in various fields of activity. A symbol, in turn, being reflected in a certain sign, an image, essential things and other forms can be a model of human activity, can define and influence on ways of ability to live which have infinite sense, the maintenance and figurativeness. If it embodies certain idea in philosophy, the great attention is given to its abstract sense in culture. There is no full and complete definition of symbol in Linguistics, whereas wide definition of it is given in semiotics. The symbols formed in period of mythology and rituals, influence the private world of a person till now. They have arised as a result of action of the various social phenomena, cases, literature and poetry, etc., thereby without losing the initial maintenance, but staying in other forms.

Symbol is very connected to mythology. Kondibai S. claims that mythology is a system of symbols (Kondibai S., 2008). Mythology is a part of people's life. Practically all people in the world have myths or mythological prints in period of its development, the same as the symbols.

Mythology can be described as an abstract understanding of reality by human being. Karasik $\mathrm{V}$. differs imaginative and conceptual means of verbal fixing of experience and claims that this is fundamental opposition of the concrete sensually perceived experience and abstract rational analitical-synthetic comprehension of reality (Karasik V. 2010). This reality is forming during the time as said Vernadski V.I. "time gives the settled cultural information on itself in its language, without making anything empty and unworthy" (Vernadski V.I., 1965).

The word "myth" usually is understood in two, opposite to each other values. In mass media this word is used as a synonym of an invention, the imagination and illusion, i.e. lie. Actually correct meaning of the word "myth" is opposite to it.

Akberdieva B. claims that myth is the result of ancient people's life and experience, tradition, inner feelings and the way of thinking (Akberdieva B., 2009).

The myth is a set of ideas and beliefs of a certain human collective of the environment of a living (time and space), about the world and its emergence, about the person, about the internal and external forces influencing the person, about a place of the society in space, etc. Thus, the Myth is not lie, artificially created thing, but the Truth of the concrete people about itself and the world.

\section{Results}

In the article we decided to combine concepts mythology and symbol and to show their interrelation. Various images taking place in myths of the different nations often become a standard; "batyrs" ('brave heroes') become idols, animals and different beings find sense and outflowing of time are perceived as symbols in human consciousness. If to consider that myth is the result of human representations and beliefs, it is possible to claim that a symbol in some degree, is the result of the myth. For example, the image of "aydakhar" ('dragon') symbolizes the following: "In mythology of Kazakhs the angry demon is depicted as a dragon (often many-headed). The dragon in world mythology is an image of water elements, but its nature is often represented with fire, as it also fire-spitting". Kondybai S. represents three images of an aydakhar. "1. In myths "aidakhar" is often perceived as a world dragon. In general the concept of snakes/ aydakhar/a dragon is interchanged. "Aydakhar" in itself is an animalistic symbol of three-level vertical model of the world: his snake body is symbolized by the terrestrial, water or underground world, his head and feet of a predator - the average, land world, and wings of a bird - the top, heavenly world. A combination of properties of three beings - the dragon, a predatory animal and a bird - allows to define an "aydakhar" as a monster, a htonichal being or a chimera. It is a mediator, i.e. it connects among themselves all three worlds.

2. Fantastic "aidakhar". In fairy tales "aidakhar" - the evil monster, its image completely corresponds to an image of the fantastic dragon existing in all fairy tales of the world ....

3. Epic "aidakhar". Prototurkic "aidakhar" - other mythical being which image is reconstructed on the basis of the Kazakh eposes..." (Kondibai S. 2013).

Thus we see that "aidakhar" has a negative image in the Kazakh culture and symbolizes the angry demon, but at 
the same time we can claim that it is a symbol of power and force as he has the power of three beings.

In the Kazakh mythology there are a lot of images of animals. For example:

"A wolf (bori, kaskyr, boltirik) one of totemic animals in Turkic, in particular, the Kazakh myth. The image of a wolf was mainly connected with a cult of the leader of a fighting team or the god of war and ancestors of a tribe.

The dog is also has mythological image in Kazakh tradition.

It. Dog - the animal who received a special place in the Kazakh all-Turkic mythology... The phrase it zhandy (the literal translation - with dog soul or having soul of dog), represents not a curse or the characteristic of the mean person, but "the firm and strong person who doesn't show the pain or despair". Presence of such phrase at language shows existence of idea of an embodiment of human soul in shape of a dog in the Kazakh myth (Kondybai S. 2008).

Snake (zhylan baba khan). According to the Kazakh beliefs, the dragon possesses sacred properties and acts as the assistant to the person in many spheres of life. The dragon symbolizes mystery, sacrality;

This is very interesting fact as not only Kazakh people can imagine snake together with huma. We can see it in "A Dictionary of symbolism": "Serpent are as different from all animals species as the human race, but at the opposite end of the scale. If mankind may be regarded as standing at the end of a long evolutionary struggle we must set this coldblooded, armless, hailess, featherless creature at its very beginning. In this sense mankind and serpents are opposites, complementary and rivals the one to the other. In this sense too, there is something of the serpent in all human beings, and strangely enough in that portion of them over which they have the least control" (Chevalier J., Gheerbant A. 1996).

The horse (at, zhylky) is attribute or image of a number of mythical characters. Mythical characters on a horse move on the sky, from one elements or the world in another. In mythology of Turkic peoples the horse possesses the special place which is explained by its role in economy and resettlements of ancient Turkic peoples" (Kondibai S. 2013).

Swan (akkhu). One of the main national symbols of the Kazakh people considering itself (according to national etymology of an ethnonym "kazakh" - "and akh khaz" - "a white swan") the descendant of a white swan. It is widespread almost at all Turkic people as the mythological character . The image of swan is sacred for the Kazakh people and symbolizes purity and beauty.

There are a lot of mythical and epic heroes who became a symbol in present time. One of them can consider Aldar Kose, who acts as a symbol of deception, cunnings, resourcefulness and mind. "E.D. Tursunov investigated this image of fairy tales and proved that it has a mythological origin. Aldar and the shaitan (or other opponent Aldara) - only the cover hiding homogeneous ancient images on which during the different periods new lines" accumulated. Alpamys, allocated with magic invulnerability, became a symbol of force, courage and power.

In Kazakh mythology quite often plants come to life and become symbols. For example, Bayterek - the World tree. Turkic version of the name of the World tree which is an element of mythological model of the world.

Bayterek (literally an initial poplar, mother poplar) as a world tree connects all three levels of the universe: top (numbering nine or seven layers of the sky), average - terrestrial, lower (the underground, numbering nine or seven layers of the sky). Its separate parts represent parts of the certain worlds: roots belong to the underground world, krone branches and leaves to the top world.

... The image of the World tree symbolizes the family relations, a continuity of generations and a family tree. Turkic people believe that people take babies from under trees (cf. option of a genealogical legend of Adaye), or that souls of ancestors live on a tree branches and leaves were widespread. ... The word bayterek is also used in clans' sign system of Kazakhs. For example, a patrimonial call and one of mythical ancestors of a tribe of a Qangly - bayterek".

There are also space symbols in mythology, it is possible to consider the Road of birds (Khus zholy). "... In modern astronomy the name the Milky Way is accepted. Modern Kazakhs call its Road of birds - "Khus zholy". ... In most cases substance of the Milky Way is considered as a certain liquid, moisture (water, milk, etc.) that is certainly connected with image of the Milky Way as the Rivers (Kondibai S. 2013).

Symbol inherited its social and communicative functions from myth. Symbol unlike allegory which can decode "stranger", in consciousness is warmth of the rallying secret. During the eras, similar to classical antiquity and the Middle Ages, people were devoted more widely to cultural and confessional communities; on the contrary, during a bourgeois era the consciousness functions within the elite environment, giving opportunity to the adherents to identify each other among "indifferent crowd". But also in this case the consciousness keeps the unity, rallying nature: "interfacing" a subject and sense, it at the same time "interfaces" people, who fell in love and understood this sense. The artist's will to overcoming of an abyss between an essence and visibility, between "whole" and "special" by the nature symbolically resists to public alienation, though doesn't win against it really (Averintsev S. 2001).

As it is known symbols also act as representation and belief of the person. Temirgazina Z. claims that: "The symbol 
is the thing awarded by sense. For example, the tree in detail, object, tangible and shown, has a form and color. In the Russian national consciousness the birch acts as a symbol of the homeland, Russia" (Temirgazina Z. 2002).

Though a symbol is so ancient as human consciousness in general, its philosophical and esthetic understanding is rather late result of cultural development. The mythological stage of outlook assumes just not dismembered identity of a symbolical form and its sense excluding any reflection over a symbol. The new situation arises in ancient art after Platon's experiments on designing of philosophical mythology of the second order, not before reflective, but postreflective, i.e. symbolical in strict sense of this word. And it was important to Platon to delimit a symbol not from discourse-rationalistic allegory, and from the before philosophical myth. The Hellenistic thinking also constantly mixes a symbol with allegory. (Averintsev S. 2001)

\section{Conclusion}

Symbol is a very ancient phenomenon being a part of the mythology. Till today we have mythological figures which can be considered as symbols or mythological symbols. The structure of symbols consists of at least two equally important parts. The direct sense is an image of a symbol, its root which provides a basis for emergence of abstract value. The figurative sense is an idea of a symbol. It differs from a direct sense on quality and can be a historical, cultural stereotype, individual and subjective. The mythology also bears in itself abstract value and has a historical link to the present myths and the main images in them, in our opinion, are defined in consciousness of the person as symbols, as result of vision of the world of our ancestors which reached us from generation to generation.

\section{References:}

Akberdieva B. (2009). Cognitive linguistics. Education guidance. Almaty: Arys.

Averintsev S. (2001). Sofia-Logos. Dictionary. 2nd ed. - K.: Spirit and Dictionary.

Bevan, E. (1950). Symbolism and Belief. Boston: Beacon Press. Beacon Hill.

Chevalier J. and Gheerbant A. (1996). A Dictionary of Symbols. London: Penguin Books.

Cirlot J.E. and Sage J. (1962). Philosophical Library. New York.

Ferguson, G. (1976). Signs and Symbols in Christian Art. NY: Oxford University Press.

Ivanov V. (1985). Structural anthropology. Moscow.

Islam A. (2003). Language in the Context of National Culture. Almaty-Astana.

Karasik, V. (2010). Language crystallization of sense. Volgograd: Paradigm.

Karasik, V.I. (2012). Language Matrix of Culture. Volgograd: Paradigm.

Kondibai S. (2008). Kazakh Mythology. Short Dictionary. Esthetics of landscapes of Mangistau. Prospect for development of tourism (monograph). Almaty: Arys.

Kondibai S. (2008). Ancient-Kazakh Mythology. 1st ed. Almaty: Arys.

Kondibai S. (2013). Dictionary of the Kazakh Mythology. Almaty: Arys.

Maslova V.A. (2004). Cultural Linguistics. 2nd ed. Moscow: Academia.

Ricoeur P. (1969). The Symbolism of Evil. Boston: Beacon Press.

Shelestiuk, Helen V. (2003). Semantics of Symbol // Semiotica. Journal of the International Association for Semiotic Studies. Vol. 144$1 / 4$.

Temirgazina Z. (2002). Modern Theories in Domestic and Foreign Linguistics. Pavlodar.

Uali N. (2007). The theoretical bases of the Kazakh word. Almaty.

Vernadski V. (1965). Some words about a noosphere (text). Moscow.

Werner, H. and Kaplan B. (1963). Symbol Formation. NY: Clark University. 